DOI: 10.12731/2077-1770-2020-6-24-36

УДК 81-25

\title{
ОСОБЕННОСТИ \\ ИНТЕРНЕТ-ЛЕКСИКИ СОВРЕМЕННОГО КИТАЙСКОГО И АНГЛИЙСКОГО ЯЗЫКОВ
}

\section{Волоконская А.С., Рудометова А.Ю., Капитонова Н.С.}

В данной статье проводится сравнительный анализ основных моделей сокращений в китайском и английском интернет-сленге, а также особенностей их возникновения, выявляются сходства и различия выражений двух языков по типам сокращений, частоте и ситуациям их использования.

Цель статьи состоит в рассмотрении лексических единиц двух языков, выявлении схожих случаев использования сленговых выражений и анализе различия в их использовании в культурологическом, семантическом и фразеологическом аспектах.

Метод или методология проведения работы. В исследовании применялись традиционные для лингвистического исследования методы сплошной выборки, компонентного анализа и фразеологического анализа. Научная новизна статьи состочт в том, что проблематика использования интернет-лексики в китайском и английском языках недостаточно изучена.

Результаты. В результате выявлены не только общие закономерности возникновения и использования лексических единиц в китайском и английском интернет-сленге, но и специфические особенности их употребления в каждом из языков.

Область применения результатов. Данный материал можно использовать на практических занятиях китайского и английского языков по письменному переводу, а также для более углубленного изучения современного китайского и английского языков.

Ключевые слова: китайский язык; акроним; аббревиатура; англищизм; сленг. 


\section{SPECIFIC FEATURES OF THE MODERN CHINESE AND ENGLISH INTERNET LEXIS}

\section{Volokonskaya A.S., Rudometova A.U., Kapitonova N.S.}

This article analyses comparative study of the main ways of clipping in Chinese and English Internet lexis, and also particularities of their formation. Similarities and differences in the ways of formation of new expressions and frequency and situations of their use are also introduced in the article.

Purpose of the article is to view lexical units of the two languages, to find out similar ways of using slang phrases and to analyze the differences of their use in cultural, semantic and phraseological aspects.

Methodology. Traditional methods for linguistics as the continuous sampling method, componential analysis and phraseological analysis were used. Scientific novelty of the article is that the issue of Chinese and English Internet lexis is poorly known.

Results. Both general regularity of Internet lexis and specific ways of word-formation in Chinese and English are identified.

Practical implications. The results of the research can be used in the classes of written and oral translation of the Chinese and English languages and in-depth study of modern Chinese and English.

Keywords: Chinese; acronym; abbreviation; English loanword; slang.

Язык по своему определению не может быть статичен, это живая и постоянно развивающаяся система. Статичность и неизменяемость языка ведет к его словарному истощению, такой язык обречен на вымирание. Постоянно обновляющийся лексический состав языка сохраняет свою актуальность для исследований, а изучение возникающих в нем новых единиц и способов их возникновения позволяют более углубленно понять систему современного языка. Современный разговорный язык подвержен влиянию других языков и культур, в связи с техническим и культурным прогрессом количество новых слов быстро растет, многие из новых выраже- 
ний закрепляются в языке, видоизменяясь согласно особенностям языка, некоторые же выражения уходят вместе с исчезновением определенной моды или явления. Современные слова и выражения, используемые в интернет-общении, нередко сленговые, представляют собой крупный пласт наиболее быстро меняющейся лексики, который называют наиболее живой частью языка в связи с его переменчивостью: популярные сленговые выражения быстро приживаются в языке, но не остаются надолго, сменяясь новыми. В данной статье мы рассмотрим некоторые наиболее актуальные для анализа типы выражений китайского и американского английского языков, а именно сокращения, англицизмы, графический сленг и ситуативные выражения.

Методологическая база для исследования сленговых выражений в культурологическом, семантическом и фразеологическом аспектах была заложена в работах Е.А. Бабенковой (2015), Ван Синхуа (2017), И.Р. Гальперина (1956), Ли Сяобай (2018 и др.), Ли Сяогэ (2017), Е.Д. Полетаевой (2016), Я.П. Сагеева (2015), О.О. Синишина (2014), К.Д. Тамбовцева (2015), А.А. Хаматова (2006), O.V. Sokolovskaya (2015), R. Spears (1982).

Языковой материал исследования представлен китаеязычным медиапространством. В исследовании примерялись традиционные для лингвистического исследования методы сплошной выборки, компонентного анализа и фразеологического анализа. Выбор методов определяется спецификой объекта и предмета исследования.

Говоря о письменном разговорном китайском языке, нельзя не отметить то, что он выделяется особой эргономичностью. Стремление сэкономить время, сокращая употребляемые выражения для личного удобства, привело к возникновению большого количество разного рода сокращений, позволяющих варьировать значение лексической единицы в зависимости от ситуации коммуникации. Как замечает Е.А. Бабенкова: «Одним из главных факторов, определяющих вариативность содержания, является изменение ситуативного контекста» [1, с. 370].

В современном китайском языке интернет-общения акронимы и аббревиатуры является одним из самых распространённых ти- 
пов выражений. Акроним представляет собой вид аббревиатуры, образующийся начальными звуками, и в отличие от других видов сокращений, войдя в язык, воспринимается цельным словом, и могут употребляться как самостоятельные слова, подвергаясь изменениям, характерным языку, в котором он используется. Большинство ученых определяет акронимы как аббревиатуры в значении «инициальное сокращение». В.И. Заботкина, а также О.С. Ахманова, И.В. Арнольд и В.В. Борисов считают, что отличие акронимов от аббревиатур, состоит в том, что первые произносятся как полные слова [6, с. 917-920].

Сокращение китайских слов строится по нескольким моделям, при этом усекаются часть компонентов, оставляя смыслообразующие, например, словосочетание 业余大学 Yèyúdàxué (университет с заочным обучением) сокращается до 业大 Yèdà. При любой модели сокращения или замене части словосочетания, значение исходного и конечного выражения остается одинаковым. При этом обе формы могут параллельно сосуществовать в языке, или же конечная полностью вытесняет исходную.

Сокращенные слова и выражения также активно заимствуются в китайский язык из других языков, преимущественно английского, при этом редко видоизменяясь. Например, сокращение BF используется молодыми китайцами в интернет-общении, заменяя более длинное китайское 男朋友 nánpéngyou (парень).

Сокращения, употребляемые в китайском и в английском языке, можно условно разделить на две большие группы, они могут быть чистыми и смешанными. В состав смешанных могут входить цифры, что характерно для английского и китайского языков, но существуют также уникально китайские виды смешанных сокращений - с добавлением иероглифов или пиньиня. Примером чисто буквенных акронимических выражений в английском языке являются: ACHT - Average Call Hold Time, TAJ - Tom and Jerry, TATT - Tired All The Time (medical diagnosis in-joke), TCW - Tasty Coma Wife, TEETH - Tried Everything Else, Try Homeopathy (medical diagnosis in-joke) и T/F - True/False (=Yes/No). Многие из таких 
выражений, используемых среди американских интернет-пользователей, прижились и в других языках, в том числе и в китайском, не претерпевая изменений.

В китайском языке подобные сокращения стали появляться все чаще, что обусловлено необходимостью сильно сократить длинные китайские выражения. При этом такие сокращения часто происходят в несколько этапов. Например, название новогоднего гала-концерта 中国 中央电视台春节联欢晚会 (Вечерний новогодний гала-концерт Центрального телевидения Китая) был сначала сокращен до春节 联欢 晚会 (Вечерний гала-концерт праздника Весны), но в конце концов стал употребляться как 春晚.

В английских акронимах и аббревиатурах могут появляться цифры, которые заменяют часть слова. Цифры в таких случаях соответствуют фонетической недостающей части слова - h8, 18er, b4, f9,10q, 10x. Характерной особенностью китайских сокращений является их многообразие. Китайские акронимы и аббревиатуры куда разнообразнее. Это непосредственно связано со структурой китайского языка, что дает практически бесконечные возможности для того, чтобы сделать интернет-язык красочнее и индивидуальнее.

Желая сэкономить время, многие китайцы пользуются так называемыми смешанными сокращениями - когда часть слова написана в пиньинь, а другая часть заменена иероглифом. Например, в сло-

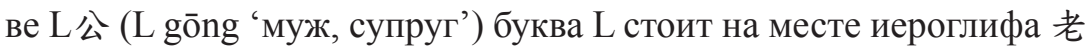
lăo, заполняя собой пустующее место. Морфема 公 gōng, стоящая рядом, наделяет букву значением отсутствующего аффикса $⿱ ⿻ 土 ㇒ 匕$ lăо. K такому же типу относятся такие слова, как L婆 (L po; 老婆 lăopo 'супруга, жена'), е心 ( е хі̄n; 恶心 е̌xīn 'отвратительно'. Часто иероглиф, используемый на письме, может не совпадать по значению с иероглифом, который подразумевается в данном словосочетании, китайцы могут заменять фонетически похожие иероглифы друг другом. Например, словосочетание 有木有 уŏumùyǒu часто употребляется вместо 有没有 уо̆uméiyǒu.

Такие сокращения в китайском языке обусловлены сравнительно небольшим количеством слогов языка, что делает его одним из 
самых омонимичных в мире. Огромное количество омонимов обусловило появление особого вида сокращений письменного разговорного языка, свойственного только китайскому языку. Таким видом сокращения являются полностью цифровые выражения, построенные по принципу созвучия. И в английском, и в китайском языках эти сокращения пользуются популярностью на просторах Интернета. Но стоит отметить, что китайская молодежь активнее использует их. Это связано с большим количеством вариантов, с более широким и разнообразным пластом выражений данного типа, а также с размером передаваемого выражения. Китайский язык более мелодичен и сильнее развит фонетически, чем английский, а значит в нем куда больше возможностей для создания подобных сокращений. Например, английское сокращение 404 имеет значение «Couldn't find it», в китайском языке 748, читающийся как qīsìbā означает 去死吧 (qùsǐba), и имеет значение «Пойди умри», «Отстань». В английском языке посредством цифр можно передать лишь небольшие слова или словосочетания, тогда как в китайском языке такими сообщениями передаются достаточно большие фразы и предложения, например цифровой код 259758 имеет значение 爱 我就娶我吧 (Я хотел бы, чтобы ты вышла за меня замуж).

Следует отметить, что некоторые из часто встречающихся выражений, например, «я тебя люблю», могут иметь несколько цифровых вариантов, все из которых находят в употреблении одновременно. Количество цифровых кодов, используемых в интерне-сети, уже насчитывает несколько сотен, и продолжает увеличиваться. Несмотря на внушающее количество диалектов в Китае, сленговые выражения такого типа почти не делится ни по каким территориальным или иным соображениям и такие сокращения активно используются как жителями юга Китая, так и пользователями Интернета на севере страны.

Активное общение китайских интернет-пользователей с представителями других культур сказывается на количестве заимствованных сленговых выражений. К ним относятся как общеизвестные аббревиатуры, например, BRO, означающее brother (брат), так и 
полностью заимствованные слова. Из часто используемых в интернет-общении заимствованных выражений подавляющее большинство взято из английской интернет-лексики. Например, $4 \mathrm{U}$ - for you (для тебя), COS / CUZ - because (потому что), D8 - date (дата, свидание), HB2U - happy birthday to you (с днем рождения) и другие. Такие заимствования не претерпевают изменений и используются, как правило, китайцами в общении с иностранцами в Интернете, как способ подражания их культуре. Полностью заимствованные слова же, напротив, могут изменяться под влиянием норм китайского языка.

Подавляющее большинство заимствованных слов, используемых в общении интернет-пользователей, заимствуются именно из английского языка. Например, такие слова как 普拉提 pŭlātí (пилатес), 网虫wăngchóng (любитель засиживаться в Интернете) и другие. Англицизмы составляют 50\% всех заимствованных слов в китайском языке. В лексической системе китайского языка англицизмы характеризуются особым статусом. Существует несколько точек зрения использования их в китайском языке. Как показатель общественной культуры, английские и американские заимствования в какой-то степени являются показателями общественного положения людей. Объективным является тот факт, что в языковом обществе именно люди с высоким уровнем образования (например, студенты, ученые и т.д.) чаще всего склонны к использованию заимствованных слов в отличие от представителей других слоев общества $[4$, с. $65-67]$.

Большинство англицизмов, вошедших в китайских язык, видоизменили свое звучание в соответствии с фонетическими нормами китайского языка. Заимствованные слова так же получают тональность, соответствующую выбранным для записи слова иероглифам. Однако некоторые слова заимствуются без изменений, но употребляются с некоторыми особенностями, при этом не получают записи иероглифами. Например, слово out, обозначающий «вне, снаружи» имеет аналог в китайском языке 外. Ассимилируясь в китайской речи слово out стало использоваться как «быть не в теме, 
отстать», например你太OUT了 означает «ты не в теме». Другим примеров англицизма является слово feel (чувствовать). Войдя в китайский язык, оно также не получило изменений на письме, но стало аналогом 感觉 (чувства; чувствовать), оно часто используется в интернет-сети в выражении 很有 feel, обозначающим «трогательный», «атмосферный», «с чувством».

Еще одним распространенным типом интернет-лексики является графический сленг. К нему относится язык эмоджи, различные gif-изображения и вирусные картинки. Основываясь на выборке Apple за 2017 г., самым распространённым эмоджи в Америке является смеющийся до слез смайлик [7]. Практически такой же смайлик стал самым популярным и в Китае. Американцы в создании новых эмоджи делают акцент на разнообразии смайликов - больше 10 новых эмоджи для улыбки, добавляют другие цвета кожи, создают гендерно-нейтральные или гендерно-разнообразные смайлики. Для такой многорасовой и мультинациональной страны как Америка, необходимо показать разнообразие во всех жизненных аспектах, в том числе, добавляя и расширяя арсенал эмоджи. В отличие от англоязычных пользователей, китайцы выбирают графические изображения с учетом особенностей своего менталитета, делая упор на две самые распространённые для них эмоции - смущение и выражение уважения. В китайском аналоге американского приложения WhatsApp - WeChat можно найти около 7 смущающихся смайликов.

Также, китайские пользователи куда активнее используют различные gif-изображения. Целью подобных картинок является максимально гипертрофированная демонстрация своего состояния. Например, на них изображены спящие животные (панды, собаки породы шиба-ину). С помощью таких гиф-изображений китайцы показывают, что им лень что-то делать, или они хотят отдохнуть. Американские пользователи Сети реже используют gif-изображения, при этом самыми популярными являются gif-изображения с эмоцией «facepalm» или «thumb up». Вирусные картинки, например, пожелания счастливого Нового Года или поздравления с праздниками, не пользуются особой популярностью у американцев, чего 
нельзя сказать о китайцах, где картинки с пожеланиями счастья в Новом Году мгновенно заполняют все чаты в предпраздничные дни. Чаще всего эти картинки репрезентируют китайскую культуру - преобладание красного и золотых цветов, парных надписей и типичного китайского оформления - узоров и завитков.

Сравнив примеры графического сленга, преобладающие в общении у китайских и американских пользователей, можно прийти к выводу, что на использование эмоджи и gif-изображений больше всего влияет культурологический и национальный контекст. Современные англоговорящие пользователи Сети предпочитают стандартные эмоджи, имеют достаточно широкий гендерный и расовый выбор в их использовании, реже используют gif-изображения и вирусные картинки, основное предпочтения отдается изображениям юмористического характера. В то время как китайцы отдают предпочтение разнообразному графическому сленгу, максимально приближенному к китайской культуре и менталитету китайского народа.

Последним видом сленга, рассматриваемым в данной статье, является «ситуативный» сленг. На волне роста популярности телевизионных сериалов и реалити-шоу образовался и новый вид сленга - случайно сказанные актерами или вовсе вырванные из контекста фразы из кинофильмов, которые мгновенно становятся хитом Интернета. В американский сленг такие выражения приходят в основном из Твиттера популярных людей и чуть в меньшей степени из фильмов и сериалов, в то время как китайский словарный запас в основном пополняется с помощью ставших в одночасье крылатыми фразами из китайских фильмов и сериалов.

Например, вирусной фразой в 2017 г. стала фраза Дональда Трампа «see you in court», которую он использовал в Твиттере, выразив этим самым свое недовольство решением суда, когда он потерпел юридическое поражение и суд отказался восстановить его мусульманский запрет. Буквально за сутки Интернет взорвался тысячами подобных твитов, где уже в свою очередь высмеивали выбор слов главы государства. Сейчас эту фразу используют в основном в шутливом значении, чтобы показать раздутую и глупую обиду и 
доказать свою правоту. Еще одним известным примеров является фраза из научно-фантастического сериала «Стартрек» «Beam me up, Scotty» используется для выражения намерения попробовать все и сразу, когда кто-то хочет помочь в безысходной ситуации, или даже как название синтетического наркотика.

В китайском языке какие-либо высказывания публичных лиц обычно не превращаются в вирусные выражения, а вот фразы из фильмов, ток-шоу и сериалов быстро расходятся по Интернету. Например, словосочетание 雨女无瓜 yǔ nŭ wú guā звучит похоже на 与你无关 yǔ nǐ wú guān, которое переводится как «не имеет к тебе отношения» или «не твое дело». Зрители заметили, что герой телесериала под названием 巴啦啦小魔仙 говорит с сильным акцентом, и нашли это забавным. После чего начали коверкать и другие слова по такому же принципу. Так не только неправильное произношение, но и неправильное написание просочились в Интернет и получило бешеную популярность.

Хорошим примером является то, как в зависимости от ситуации и под влиянием контекста обыкновенная аббревиатура OMG, которая в классическом понимании переводится как «О мой Бог» и используется для выражения удивления, резко поменяла свое значение. В 2019 г. ОМG в китайском Интернете прочно ассоциировались с яркими помадами и успешными продажами. Этому поспособствовал李佳琪Ли Цзяци, известный бьюти-блогер, рекламирующий на своём канале косметику и парфюмерию. В одном из своих обзоров он, характеризуя новую дорогостоящую помаду, произнес: «Oh my god!», чем спровоцировал волну заказов, распродав 15 тыс. новых помад буквально за пять минут. Теперь китайские пользователи используют аббревиатуру OMG в значении «истратить все деньги», «тотчас же скупить всё» и «с ума сойти! надо брать».

Рассмотрев данные примеры, мы можем увидеть, что и в китайском, и в американском интернет-сленге существуют разнообразные выражения, появившиеся во многом благодаря определенному контексту - речи политика или новой серии ситкома. Нельзя строго задать какие-либо рамки, например, временные (насколько быстро 
фраза выйдет из употребления) или указать какие-то животрепещущие темы, которым отвечают такие выражения. Зачастую, они появляются и угасают стихийно. Никогда нельзя предугадать, какая и чья следующая фраза может стать интернет-хитом и возможно задержаться в языке на пару лет.

Таким образом, рассмотрев основные особенности появления популярных интернет-выражений, можно сделать вывод о том, что, несмотря на абсолютно разный строй языков, китайский и американский сленг имеют много общего. Невозможно было бы представить современный китайский Интернет-язык без каких-либо заимствований из английского. Английские слова не просто входят в китайский молодежный сленг, а получают в нем морфологическое оформление. Это говорит о способности китайского языка поглощать и перерабатывать разнородные языковые материалы. Процесс самостоятельного образования подобной лексики из китайского языкового материала показывает, что инородные нововведения больше походят на игру, состязание молодых носителей жаргона в остроумии и острословии. Язык интернет-общения, будучи языковым пластом, обновляется каждый год, в него приходят новые выражения, какие-то исчезают вовсе. Наблюдение за появлением, формированием и развитием интернет-лексики сохранит свою актуальность в будущем.

\section{Список литературы}

1. Бабенкова Е.А. Вариативность содержательность составляющей ритуальных жанров в политическом дискурсе // Перевод в меняющемся мире: Материалы Международной научно-практической конференции, г. Саранск 19-20 марта 2015 г. М.: Азбуковник, 2015. С. 369-373.

2. Ван Синхуа. Русские и китайские молодежные жаргонизмы как проявление национальной лингвокультуры и объект научного исследования. // Сибирский филологический журнал. 2017. № 3. 2017. С. 248-256.

3. Гальперин И.Р. О термине «сленг»// Вопросы языкознания. 1956. №6. С. 107-114.

4. Ли Сяобай, Полищук Е.В. Заимствования из английского языка в китайском языке (методический аспект) // МНКО. 2018. №4(71). С. 65-67. 
5. Сагеева Я.П. Китайские сложносокращенные слова как особая часть китайской лексики // Молодой ученый. 2015. №11(91). С. $1681-1683$.

6. Синишина О.О. Интернет-лексика в современном китайском языке // Вестник Моск. ун-та. Серия 13. Востоковедение. 2014. №3. C. 57-63.

7. Apple reveals most popular emoji in US. URL: https://blogs.voanews. com/all-about-america/2017/11/06/apple-reveals-most-popular-emojiin-us (дата обращения: 15.04.2020).

8. Sokolovskaya O.V. The Chinese-Russian slang as a contemporary aspect of the Russian-Chinese language contact // Journal of Siberian Federal University. Humanities \& Social Sciences. 2015 No 8(12). P. 2953-2959.

\section{References}

1. Babenkova E.A. Perevod v menjajushhemsja mire [Translation in a changi.g world]. Materialy Mezhdunarodnoj nauchno-prakticheskoj konferencii, g. Saransk 19-20 marta $2015 \mathrm{~g}$ [Translation in a changing world: Materials of the International Scientific and Practical Conference, Saransk, March 19-20, 2015]. Moscow: Azbukovnik, 2015. P. 369-373.

2. Wang Xinghua. Sibirskij filologicheskij zhurnal [Siberian philological journal], 2017, no 3. P. 248-256.

3. Halperin I.R. Voprosy jazykoznanija [Questions of linguistics], 1956, no 6. P. 107-114.

4. Li Xiaobai, Polishchuk E.V. Mir nauki, kul'tury, obrazovanija [The world of science, culture, education], 2018, no 4 (71). P. 65-67.

5. Sageeva Y.P. Molodoj uchenyj [Young scientist], 2015, no 11(91). P. 1681-1683.

6. Sinishina O.O. Vestnik Moskovskogo universiteta [Moscow University Bulletin], 2014, no 3. P. 57-63.

7. URL: https://blogs.voanews.com/all-about-america/2017/11/06/applereveals-most-popular-emoji-in-us (accessed 15.04.2020).

8. Sokolovskaya O.V. Journal of Siberian Federal University. Humanities \& Social Sciences, 2015, no 8(12). P. 2953-2959. 


\section{ДАННЫЕ ОБ АВТОРАХ}

Волоконская Анастасия Сергеевна, студент ГЛ-41, факультет социально-гуманитарный, кафедра лингвистика и иностранные языки Донской Государственныий Технический Университет пл. Гагарина, 1, г. Ростов-на-Дону, 344003, Российская Федерация avolokonskaya44@gmail.com

Рудометова Анастасия Юрьевна, старший преподаватель кафедры лингвистика и иностранные языки

Донской Государственный Технический Университет пл. Гагарина, 1, г. Ростов-на-Дону, 344003, Российская Федераиия nastasiacom@bk.ru

Капитонова Нина Сергеевна, доцент кафедры лингвистика и иностранные языки, кандидат филологических наук Донской Государственный Технический Университет пл. Гагарина, 1, г. Ростов-на-Дону, 344003, Российская Федерация neonilak@inbox.ru

\section{DATA ABOUT THE AUTHORS}

Volokonskaya Anastasia Sergeevna, Student, Social and Human Faculty, Department of Linguistics and Foreign Languages Don State Technical University

1, Gagarin Sq., Rostovv-on-Don, 3440003, Russian Federation avolokonskaya44@gmail.com

Rudometova Anastasia Urevna, Senior Lecturer, Department of Linguistics and Foreign Languages Don State Technical University 1, Gagarin Sq., Rostovv-on-Don, 3440003, Russian Federation nastasiacom@bk.ru

Kapitonova Nina Sergeevna, Associate Professor, Department of Linguistics and Foreign Languages, Ph. D. in Philology Don State Technical University 1, Gagarin Sq., Rostovv-on-Don, 3440003, Russian Federation neonilak@inbox.ru 